\title{
$\mathrm{PH} 104_{\text {debate }}$
}

a debate Patrimonio cultural y cambio climático

| coordina Alejandro García Hermida

\section{Arquitectura por el cambio climático}

José Franqueira Baganha | arquitecto, INTBAU-Portugal

URL de la contribución <www.iaph.es/revistaph/index.php/revistaph/article/view/4977>

Agradezco a este debate la oportunidad de compartir algunas reflexiones sobre problemas actuales y futuros que pueden surgir de la situación de emergencia que estamos viviendo, una emergencia ambiental y civilizatoria, y sobre la contribución de la arquitectura para que los edificios y lugares que diseñamos, o en los que intervenimos, se adapten mejor a las circunstancias climáticas.

No debemos omitir de esta reflexión el hecho de que el estado de la cuestión de la edificación, desde hace ya algunas décadas, podría considerarse inadecuado y peligroso para nuestra existencia (e incluso supervivencia) como especie. No será necesario describir (porque es sabido) toda la sucesión de errores, casi siempre desastrosos, que se repetían y acumulaban en la forma de construir los edificios y cómo las ciudades crecieron, algunas, o se vaciaron, otras, en el uso continuado de soluciones, tecnologías y materiales profundamente nocivos para la salud del planeta.

Las razones y los modelos que han contribuido a este "desastre" son conocidos, lamentablemente, demasiado bien, por cualquiera, aunque sorprendentemente (o quizás no) no todos asumen esta realidad y continúan actuando como si nada ocurriera, precipitándose al abismo en un proceso autodestructivo, ciego, a veces incluso con arrogancia y soberbia, arrastrándonos también al resto. La legislación y los modelos de enseñanza vigentes están muy lejos de poder dar respuesta a estos problemas, más o menos nuevos, y como consecuencia las instituciones públicas y las principales entidades de referencia también.

Coincidiremos todos reconociendo que el modelo de crecimiento de las ciudades basado en teorías de zonificación, separación de usos y concentración monofun-

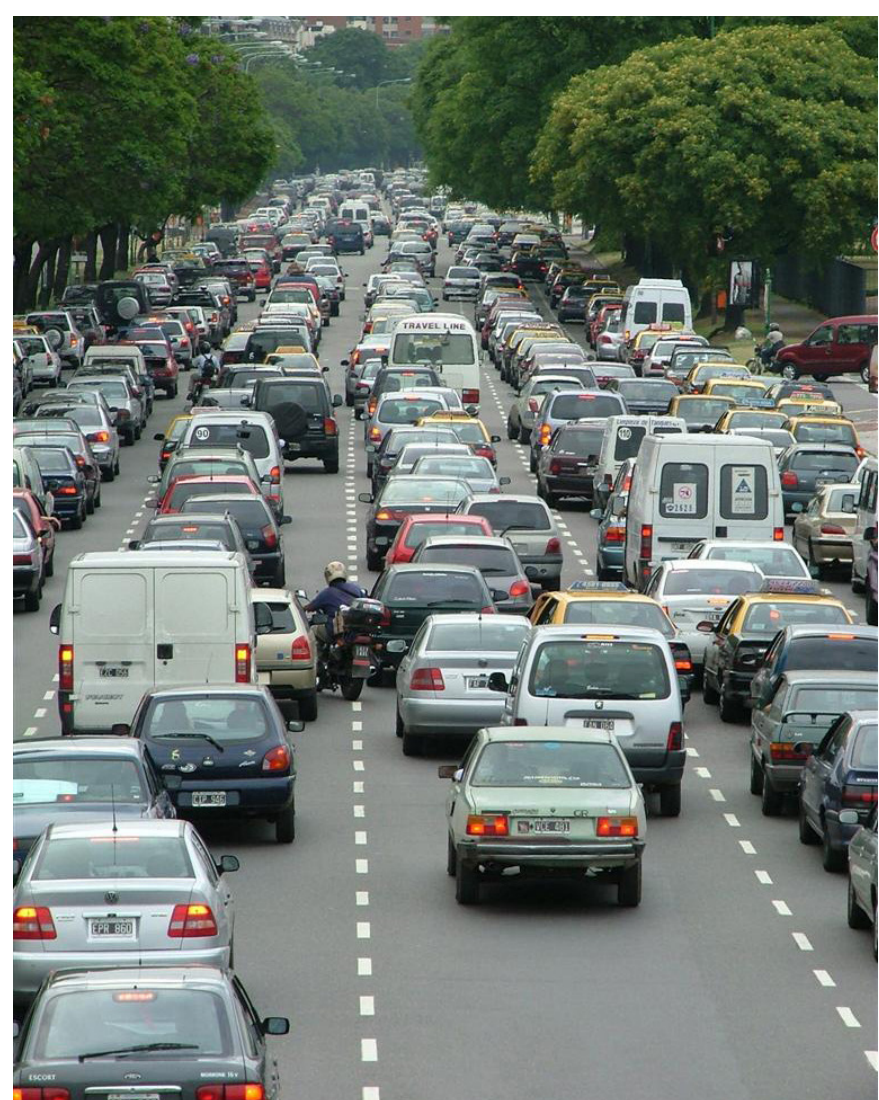

Excesiva congestión de tráfico en áreas urbanas | foto Luis Jou García

cional excesiva, genera necesidades inconmensurables en el movimiento de personas desde los lugares donde duermen a los que trabajan, estudian, se abastecen, etc., con la consiguiente e igualmente inconmensurable necesidad de infraestructura vial y de transporte, evidentemente insuficiente. De tal manera que es urgente corregir este estado de cosas.

¿Qué podemos hacer entonces? Tendremos que contrarrestar el desarrollo autodestructivo y promover el desarrollo sostenible. No hay duda de que el cambio no 
depende solo de los arquitectos (sería presuntuoso asegurar algo así) pero sí desde la arquitectura se puede realizar una significativa contribución al cambio, como se ha hecho en otros tiempos.

Nos referimos a cambios fundamentales, más urgentes, como eliminar de una vez por todas de la legislación todo el lastre de la política de zonificación, y promover una práctica basada en la mezcla de usos en los diferentes barrios, es decir, pensar la ciudad en unidades vecinales lo más autónomas posible en relación con necesidades básicas. Todo lo que es esencial para nuestra existencia debe estar a una distancia de 10 o 15 minutos como máximo. No debería ser necesario subirse a un autobús o en un automóvil para comprar un litro de leche o un medicamento, la escuela tampoco tiene que estar a kilómetros de distancia y los niños deberían poder acceder a ella de modo sencillo en bicicleta, a pie, solos o acompañados.

Entonces, aquellos servicios de uso más esporádico (el centro de salud, los servicios de apoyo ciudadano, el consejo parroquial o el departamento de finanzas, por ejemplo) pueden ubicarse en las áreas de separación de los diferentes barrios, junto con parques públicos, infraestructuras deportivas y de espectáculos.

Los servicios más importantes, como ministerios y otros departamentos gubernamentales, lugares de culto, grandes empresas... pueden estar dispersos por el tejido urbano, aprovechando los sitios más céntricos de cada barrio (plazas, avenidas principales...) y, localizadas en zonas limítrofes, las industrias.

Las ciudades deben tener límites claros y bien definidos que las separen del campo y otros tipos de ocupaciones de territorio, y deben contener, en sí mismas, estructuras de espacios libres, ajardinados y arbolados, tanto públicos como privados, que aseguren un adecuado equilibrio con el espacio edificado y colaboren en aspectos esenciales como infiltración de suelos, protección de acuíferos y drenaje de agua de lluvia o canales de aireación. Estos espacios también invitan a la convivencia y el

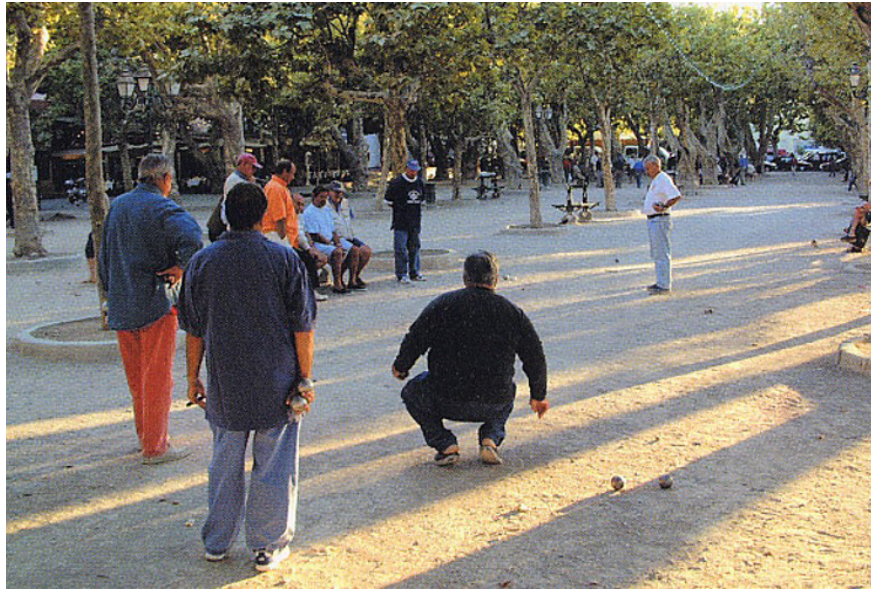

Place des Lices, Saint-Tropez, Francia | foto José Franqueira Baganha

esparcimiento de poblaciones en condiciones de proximidad. Espacios sociales fundamentales para la salud mental de las personas y para una sociedad también sana y verdaderamente próspera en todos los ámbitos.

La noción de "espacio canal", la calle, es igualmente esencial. La ciudad no funciona bien sin estos espacios. Las calles, en lugar de las carreteras que atraviesan y "cortan" nuestras ciudades, garantizan la movilidad, las relaciones vecinales, la seguridad y constituyen el espacio por excelencia para las actividades que complementan la vivienda (como el comercio, los servicios públicos del barrio, la escuela, etc.).

Además de la importancia de la calle en el funcionamiento de nuestras ciudades, existen otros elementos básicos que han demostrado, a lo largo de los siglos, su eficacia en el contexto de una experiencia urbana sana, segura y feliz: la manzana, su oferta variada, dependiendo del nivel de ingresos de los ciudadanos, permite asegurar una mezcla sana y rica, que siempre ha estado presente en las ciudades, como contrapunto a los actuales guetos de ricos y pobres, y el desplazamiento de las clases medias a los suburbios-dormitorios.

Al mismo tiempo, se deben adoptar medidas atractivas y efectivas que supongan un incentivo para que la población pueda instalarse en centros urbanos más peque- 
a debate Patrimonio cultural y cambio climático

| coordina Alejandro García Hermida

ños (en ciudades pequeñas y medianas), para frenar y revertir, en la medida de lo posible, el éxodo hacia la gran metrópoli. La llegada de Internet tiene desventajas, pero también nos brinda nuevas y buenas posibilidades: el ejercicio de la profesión en la actualidad, en muchos casos, puede realizarse desde casa o en otro lugar, sin requerir la presencia constante en el servicio, en la oficina o en el estudio. El espacio y el tiempo de trabajo, hoy, ya no presupone necesariamente la lógica de jornadas "de 9 a 5" del proletariado de fábrica, esto ya es parte de la historia. Las estadísticas más recientes parecen indicar que los nuevos modelos de ejercicio laboral han dado como resultado ganancias significativas en la productividad y la calidad de vida.

El éxodo de poblaciones hacia las grandes regiones metropolitanas es un hecho inexorable, y los efectos ambientales de esta excesiva aglomeración de personas, con todo lo que ello implica en relación con infraestructuras y equipamientos, contribuye en gran medida a agravar la situación en términos de cambio climático. Los niveles de contaminación son devastadores y la calidad de vida de las personas se deteriora drásticamente.

Contrarrestar este fenómeno de desplazamiento de población es extraordinariamente difícil, pero esencial. Las medidas deben ser radicales e inmediatas, sin ellas la situación podría agravarse hasta un punto sin retorno, con efectos desastrosos para el equilibrio ambiental, como ya estamos viendo en esta era planetaria.

Si en cuanto a la ciudad que debemos formar parece que no hay duda, que, en esencia, todos estamos de acuerdo, no ocurre lo mismo en lo que respecta a los edificios, su construcción, la arquitectura en sí. ¿Podemos mejorar también en este aspecto? Sería imprescindible, y se deberían abordar algunos aspectos ineludibles: La construcción debe dar más valor a las tipologías tradicionales, de región a región, tomando de las construcciones vernáculas las valiosas lecciones que nos brindan, promoviendo el uso de materiales y tecnologías de producción local, regional, con resultados probados de idoneidad para los lugares en los que se ubican las edi- ficaciones y menos la lógica de gran producción industrial, en serie, con efectos sumamente nocivos para el medio ambiente y, por tanto, para nuestra salud. Esta apuesta también contribuye a la creación de empleo y asentamiento de poblaciones en las zonas más sujetas al abandono.

También en estos asuntos, la legislación y los planes de estudios académicos deben cambiar. El sistema está diseñado de tal manera que muchas de las soluciones más adecuadas no pueden ser aprobadas por las distintas instituciones que licencian las obras. Construir con tierra (tapial, adobe, etc.), madera o piedra sin añadir materiales artificiales producidos industrialmente como poliestirenos, polietileno, aluminio, plástico, etc. es casi imposible.

Si tenemos en cuenta el efecto de la producción de estos materiales sobre el cambio climático, la contaminación del aire, de ríos y océanos, rápidamente concluimos que hay que cambiar, ahora.

Se necesita coraje, voluntad de cambio, determinación, pero sin esta transformación nos dirigimos inevitablemente hacia el desastre.

No creo que el uso de materiales y técnicas de construcción tradicionales inhiba la innovación, la creatividad y la prosperidad. Esta es una de las falacias más comunes entre quienes, por razones oscuras (codicia, generalmente) o ignorancia, se resisten al cambio.

Además de semejantes hallazgos, otros son igualmente inevitables en el contexto de cambios de actitudes o paradigmas (como está de moda decir ahora). Nos referimos a aspectos que contribuyen a salvaguardar la identidad de los lugares y sus poblaciones. La preservación del patrimonio construido (monumental o no), el cuidado con el que tratamos los barrios, sus calles, plazas, jardines y edificios, la forma en que protegemos determinados lugares y "hacemos ciudad" no puede ser indiferente a esta necesidad que todos sentimos de preservar los valores de nuestra historia, de la memoria colectiva, 
de la identidad que nos distingue, de región en región, de barrio en barrio, incluso en un mundo cada vez más globalizado.

La "política del espectáculo" (del Star Business), definitivamente, debe dar paso a prácticas de verdadera ciudadanía y sentido común.

Otra noción que parece muy pertinente en estas materias es la longevidad de los edificios y espacios públicos que diseñamos. La noción de longevidad aplicada a la construcción y la arquitectura ya no se basa solo en el hecho de que los edificios deben ser duraderos (lo cual es básico) sino también en la posibilidad de que sean cada vez más susceptibles de adaptarse al paso del tiempo y a las diferentes formas y modos de uso.

Los valores de libertad, paz, seguridad o amor deberán volver a estar en la base de una estética que integre a la humanidad en el orden cósmico, articulando factores materiales y espirituales.

En los tiempos venideros, los arquitectos y otros agentes que intervienen en nuestras ciudades, pueblos, aldeas y territorios, así como en los edificios, se enfrentarán a desafíos extraordinarios, difíciles, pero también emocionantes y estimulantes. De modo que todos sepamos cómo aprovechar esta rara oportunidad de participar en el cambio.

\section{BIBLIOGRAFÍA}

- Adam, R. (2008) Globalization and Architecture: The challenges of globalization are recently shaping architecture's relationship with society and culture. The Architectural Review, n. ${ }^{\circ} 223(1332)$, pp. $74-77$

- Adam, R. y Hardy, M. (ed.) (2008) Tradition Today, Continuity in Architecture and Society. Southtampton: INTBAU, WITPress

- Asquith, L. y Vellinga, M. (ed.) (2006) Vernacular Architecture in the Twenty-First Century, theory, education and pratice. New York: Taylor \& Francis

- Chueca Goitia, F. (1989) Breve história do urbanismo. 2.a edición. Lisboa: Editorial Presença
- Franqueira Baganha, J.A. (2006) Casas com tradição. Lisboa: Editorial Caleidoscópio

- Jacobs, J. (2003) Morte e vida de grandes cidades. S. Paulo: Martins Fontes

- Krier, L. (1999) Arquitectura: escolha ou fatalidade. Lisboa: Estar

- Lino, R. (1945) Quatro Palavras sobre Urbanização. Lisboa: Valentim de Carvalho

- Maillard, Ch. (1992) La creación por la metáfora: introducción a la razón-poética. Barcelona: Anthropos

- Olgyay, V. (1998) Arquitectura y clima, manual de diseño bioclimático para arquitectos y urbanistas. Barcelona: Ed. Gustavo Gili

- Portoghesi, P. (2005) Geoarchitettura, verso un'architettura della responsabilità. Milano: Skira editore

- Sitte, C. (1992) Aconstrução das cidades segundo seus princípios artísticos. S. Paulo: Ática

- Sola-Morales, M. (1997) Las formas de Crecimiento Urbano. Barcelona: UPC

- Távora, F. (1962) Da organização do espaço. 1.ª edición. Porto: FAUP

- Venturi, R. (1984) Complexity and Contradictions in Architecture. 2. ${ }^{\text {a }}$ edición revisada. New York: The Museum of Modern Art 